\title{
FICÇÃO E GUERRILHA DO ARAGUAIA: ELEMENTOS REVISIONISTAS NO ROMANCE PALAVRAS CRUZADAS, DE GUIOMAR DE GRAMMONT
}

\author{
Carlos Augusto Carneiro Costa ${ }^{1}$
}

Resumo: Em 2015 veio a público pela editora Rocco o romance Palavras cruzadas, da escritora Guiomar de Grammont. Em um momento político relativamente diferente àquele em cujo terreno germinaram obras de maior envergadura contestatória do regime militar, a obra parece apresentar, no plano da ficção brasileira, uma visão talvez ainda inédita sobre as relações entre um guerrilheiro, sua família e os militares. O presente artigo procura elaborar uma reflexão crítica sobre o problema da memória e do esquecimento suscitado no processo narrativo do romance. Por meio de análise interpretativa feita em perspectiva histórica, buscamos avaliar o modo como o recente passado brasileiro é reinterpretado na referida obra. Para tanto, estudos de Paul Ricœur, Freud, Goeffrey Hartman e Susan Suleiman serão explorados.

Palavras-chave: Memória; Esquecimento; Guerrilha do Araguaia.

\begin{abstract}
In 2015 it was published by Rocco Editor the novel Palavras cruzadas, by Guiomar de Grammont Brazilian writer. In a political moment somewhat different to that in which ground germinated works of greater power of contest the military regime, the work seems to have, considering the Brazilian fiction status, a vision perhaps even unprecedented on the relationship between a guerrilla, his family and the militaries. This article seeks to develop a critical reflection on the problem of memory and forgetting raised in the narrative process of the novel. Through interpretative analysis in historical perspective, we seek to assess how the recent Brazilian past is reinterpreted in such work. To this end, studies by Paul Ricœur, Freud, Goeffrey Hartman and Susan Suleiman will be explored.
\end{abstract}

Kaywords: Memory; Forgetting; Araguaia's Guerrilla.

"Não há castigo apropriado para um crime desproporcional. Nesse sentido, tais crimes constituem um imperdoável de fato".

Paul Ricœur

\footnotetext{
${ }^{1}$ Doutorando do Programa de Pós-Graduação em Estudos Literários (área de Teoria da Literatura e Literatura Comparada), da Universidade Federal de Minas Gerais (UFMG). Professor Assistente de Estudos Literários do Instituto de Estudos do Xingu, da Universidade Federal do Sul e Sudeste do Pará (UNIFESSPA). E-mail: carl.lo.sac@hotmail.com.
} 


\section{Introdução}

Geoffrey Hartman (2000), no ensaio "Holocausto, testemunho, arte e trauma", aponta que a intelectualidade do pós-guerra vem produzindo uma gama excessiva de conhecimento a respeito das catástrofes provocadas pela Segunda Guerra Mundial, principalmente aquelas ligadas aos campos de concentração nazistas. Na mídia e no campo cultural, esses episódios históricos também vêm sendo vastamente apresentados e representados, respectivamente, em razão de seus impactos determinantes na trajetória da humanidade. Normalmente, a exposição desses eventos tende a recorrer a mecanismos de apresentação e representação espetacular, promovendo certa banalização dos processos de violência neles contidos. Com isso, torna-se necessário pensar, conforme Hartman, nos limites dessas formas de lidar com o passado violento. Hoje tudo é representável, o problema é refletir sobre como representar e qual a finalidade dessa representação. Ainda segundo o autor, "levar a sério as formas de representação significa reconhecer o seu poder de mover, influenciar, ofender e ferir. É por isso que esse tema conservador, dos limites da representação, é importante" (HARTMAN, 2000, p. 208).

A produção literária brasileira, inserida principalmente no contexto da ditadura militar e, em certa medida, no período pós-ditadura, pode ser pensada na linha dessa vasta produção que procura compreender, através da representação ficcional, o conflituoso processo histórico ditatorial no Brasil. Iniciada com a publicação do romance Quarup, de Antônio Callado, em 1967 (obra ainda essencialmente imbuída de um espírito romântico-revolucionário), essa produção procurou representar desde os movimentos mais otimistas sobre a derrota da ditadura (caso de Quarup), passando pela representação do reconhecimento da impossibilidade de derrotar a ditadura (caso do romance Em câmara lenta, de 1977, de Renato Tapajós) até chegar a um conjunto de romances que não tematizam diretamente os horrores da ditadura, mas são ambientalizados nela e tocam direta ou indiretamente em problemas ligados a esse período, como no caso do romance Cinzas do Norte, de Milton Hatoum, publicado em 2005.

Em 2015, veio a público, pela editora Rocco, o romance Palavras cruzadas, da escritora Guiomar de Grammont. Em um momento político |36| 
relativamente diferente àquele em cujo terreno germinaram obras de maior envergadura contestatória do regime militar, a obra parece apresentar, no plano da ficção brasileira, uma visão talvez ainda inédita sobre as relações entre um guerrilheiro, sua família e os militares.

Neste estudo, pretendemos refletir a respeito dessa inquietante narrativa, procurando pensar nas suas relações com o tema da memória e do esquecimento, a partir dos traços revisionistas que nossa leitura trouxe à luz. Por revisionismo entendemos aqui $o$ ato de reinterpretação do passado conflituoso, em que a perspectiva do algoz normalmente é sobreposta à da vítima, numa difícil tentativa de negação da versão desta última sobre o processo de violência vivido, ou de elaboração de um discurso que põe em um mesmo patamar o grau de responsabilidade pelos crimes cometidos.

\section{Ficção e guerrilha}

A história é estruturada em torno da busca da jornalista Sofia por notícias a respeito do paradeiro de seu irmão Leonardo, militante de uma organização guerrilheira que lutava contra o regime militar no Brasil, e que era dado como desaparecido desde 1972, quando Sofia tinha apenas dez anos. Mas é somente com a morte do pai, em 1992, que a jornalista decide empreender a busca, em parte motivada pelo sofrimento incessante que 0 desaparecimento do irmão havia causado à família, em parte pela necessidade de divisão da herança deixada pelo pai, que exige a presença física dos herdeiros. Sua busca também é catalisada pela leitura de um diário, escrito em 1972, que chega a suas mãos através de seu amigo Marcos, que, quase no meio da história, Ihe revela ter sido sua própria mãe, Luísa, quem Ihe pediu para entregar e manter sigilo por algum tempo. Assim, o romance é tecido por "palavras cruzadas" que imprimem um caráter descontínuo e fragmentário à história, contada por pelo menos cinco vozes narrativas: a de Leonardo, que escreve a segunda parte do diário; a de Mariana, sua namorada, que escreve a primeira parte do mesmo diário; a do pai de Leonardo, em carta dirigida ao filho; a de sua mãe, também em carta dirigida a Leonardo; e a da própria narradora em terceira pessoa que, por meio da focalização de Sofia, organiza 
todo o percurso narrativo com elevado grau de estabilidade, garantido por sua perspectiva onisciente.

A busca de Sofia entorna a narrativa em vários espaços: de Belo Horizonte, onde mora, a jornalista vai a São Paulo, ao Sul do Pará, a Cuba, Brasília e Paris. A cada viagem, conversa com pessoas que de alguma forma tiveram contato com Leonardo. O cruzamento das informações obtidas nas viagens com a leitura do diário e das cartas deixadas por seu pai revela-Ihe que Leonardo havia participado do "justiçamento" de um membro de sua organização acusado de traição, e que, após esse evento, teria deixado São Paulo e viajado para o Sul do Pará, a fim de encampar foco de resistência rural, no contexto da Guerrilha do Araguaia. Mariana, sua namorada e também guerrilheira, teria engravidado e, para não ter que abortar a criança, decide voltar para São Paulo, ter o filho e retornar posteriormente à selva. Antes de deixar a Amazônia, Mariana enterra seu diário, encontrado posteriormente por Leonardo, que continua a escrita. Após semanas perdido na mata, com sua organização desmobilizada pela busca implacável dos militares, Leonardo é preso e leva consigo o diário, que é apreendido pelo coronel Monteiro, chefe da ação militar. Aproximadamente três anos após esse evento, Mariana deixa a casa dos pais junto da filha (Luísa, mesmo nome da avó paterna), e nunca mais é vista. O coronel, que teria sido o responsável pelo desaparecimento do casal, adota a criança, a quem dá o nome de Cíntia. Anos mais tarde, envia à mãe de Sofia o diário de Leonardo e Mariana.

Do ponto de vista estético, a narrativa de Guimar de Grammont pode ser inscrita em uma tendência recorrente na produção literária brasileira que faz perfeito uso dessa habilidade de articular eventos conflituosos do passado com uma experiência do presente normalmente caracterizada por traços de melancolia. Isso remonta à produção que se estende ao longo de quase dois séculos, e inclui, de maneira mais notável, escritores como Machado de Assis (Dom Casmurro e Memórias Póstumas de Brás Cubas), Graciliano Ramos (São Bernardo) e, mais recentemente, Raduan Nassar (Lavoura Arcaica), Milton Hatoum (Cinzas do Norte) e Chico Buarque (Leite Derramado). Mesmo escrevendo em pleno século XXI, cintila em sua obra um engenhoso procedimento de escrita que mantém o mistério da narrativa até seu desfecho, notado por Walter Benjamin (1994), ainda em 1936, como um dos resquícios |38| 
na modernidade da habilidade de narrar dos tradicionais contadores de histórias orais. Essa habilidade também se vincula ao que Victor Chklovski (1978) diz a respeito da boa obra de arte, cuja força reside justamente em sua capacidade de provocar estranhamento pela redução das possibilidades de compreensão imediata, pela desautomazitação da interpretação, dado 0 processo de singularização dos modos de elaboração da linguagem. Por fim, também é de Benjamin a noção de que a linguagem fragmentada, constituída por segmentos descontínuos, pode contribuir para um processo de melhor apreensão da história narrada. O leitor é levado a concentrar maior atenção diante de vários recortes narrativos, uma vez que ele se encontra diante de uma "expressão diferente e mais intensa" (1984). O romance de Grammont está adequadamente inserido nessa perspectiva benjaminiana, se considerarmos a forma caleidoscópica de sua estrutura e o minucioso trabalho de integração das informações dispersas espacial e temporalmente.

Já do ponto de vista ético, Palavras cruzadas se apresenta como um desafio à crítica literária contemporânea, pois o debate que elabora ainda se apresenta incomum, talvez até inédito, no âmbito da ficção brasileira surgida desde o golpe militar.

É sabido que se tornou lugar comum a avalanche de discursos nostálgicos a respeito da ditadura militar midiatizados principalmente ao longo dos últimos dois anos. Também é muito recorrente a percepção da trivialização e legitimação da violência policial indiscriminada contra indivíduos criminosos e não criminosos, em geral, com a justificativa de que a ação truculenta da polícia é a justa medida da ação da vítima. Colocada a questão dessa forma, parece haver na sociedade brasileira atual um movimento conciliatório e reconciliatório de partes normalmente antagônicas. Conciliatório na medida em que boa parcela da população entende que é legítimo o ato truculento diante de uma ação truculenta, até mesmo quando se trata de torturar até a morte o ser humano. Reconciliatório na medida em que a imagem afirmativa do recente passado brasileiro, caracterizado pelo autoritarismo militar, ecoa no presente daquela mesma parcela da população como possibilidade de superação dos problemas políticos atuais. O que era para ser posto em constante discussão crítica, a fim de que nunca mais se repetisse, retorna com força ainda maior e 
encontra nos diversos setores da sociedade elevado grau de aceitação. Um anseio do presente conciliado com a imagem afirmativa da ditadura militar.

Se quisermos compreender o debate proposto por Grammont, é necessário levar em conta essas questões expostas acima, pois nos parece haver, no âmbito da realidade histórica brasileira do período pós-ditadura para cá, uma estreita relação entre esses processos conflituosos e a maneira apaziguante com que o romance encerra.

Ao contrário de todos os escritores citados na página três deste estudo, cujas obras encerram com a apresentação de um quadro nada conciliatório da sociedade brasileira, o romance de Grammont parece intentar produzir aquele efeito apaziguante, na medida em que propõe a necessidade de se perdoar crimes cometidos contra a humanidade a fim de promover a reconciliação entre partes outrora conflitantes, levando ao esquecimento desse passado, sem ao menos ter havido, do ponto de vista criminal ou pelo menos moral, alguma forma de punição para o perpetrador. Objetivamente, o livro procura colocar em um mesmo patamar de responsabilidade pela violência da ditadura, torturadores e torturados, algozes e vítimas, militares e militantes, num movimento que esvazia o espaço do debate crítico e as reivindicações de justiça, por meio de vozes que reproduzem literariamente o conteúdo da Lei de Anistia, de 1979. Algumas passagens do romance podem ser ilustrativas dos problemas a respeito dos quais procuramos refletir.

A constituição da personagem Leonardo é de difícil inserção no contexto da militância guerrilheira. Em vários momentos, seu discurso ecoa com constante tom de lamento pelas condições precárias de sobrevivência na selva. É notável o grau de relevância dado a seu sofrimento pessoal em ter que enfrentar as adversidades de uma floresta: "Dormi repisando na memória a canção do guerrilheiro do Araguaia para me acalmar. Os versos que cantávamos, alegres, na hora da colheita, não tinham nada a ver com a situação que eu enfrentava agora, parecia ironia" (GRAMMONT, 2015, p. 19). Os versos aos quais se refere Leonardo são de uma canção que exalta 0 heroísmo dos que combatem contra a ditadura. Ainda no "calor da hora", em meio à guerrilha, a imagem que tem de si e da luta é elaborada por meio de uma negatividade constitutiva, tanto do ponto de vista pessoal quanto da realidade histórica: "Agora, escondido, quando o desânimo se abate sobre $|40|$ 
mim, o ufanismo ingênuo desses versos parece queimar minha garganta, tenho dificuldades em balbuciá-los" (GRAMMONT, 2015, p. 20).

Essa negatividade constitutiva é recorrente na literatura brasileira, especialmente em narradores de obras cujo debate construído gira em torno de problemas de violência de Estado. Frases com conteúdo autopunitivo também são comuns nos casos de experiências traumáticas que produzem sentimento de culpa e conduzem o sujeito a uma vivência melancólica. Entretanto, é incomum ouvir de um guerrilheiro, em pleno combate, um discurso não apenas de deserção, mas de entrega ao inimigo: "Depois de semanas sem ver um ser humano, tudo que eu queria era ser encontrado, por quem quer que fosse" (GRAMMONT, 2015, p. 25; grifo nosso). Ao invés de conduzir o leitor a uma adesão à perspectiva da personagem, enquanto vítima da violência ditatorial, essa atitude acaba desenvolvendo empatia no leitor, muito em razão da imagem de militante ingênuo sugerida ao longo de toda a narrativa.

Em entrevista realizada em 2009 com Renato Tapajós, autor do romance Em câmara lenta, é possível notar, mesmo tendo se passado quase cinquenta anos de sua participação na guerrilha urbana, elevado grau de clareza em relação aos seus objetivos e ao seu comportamento diante do terror: "eu era totalmente fechado com a ideia da luta armada. Quer dizer, a única maneira de realizar as transformações necessárias - derrubar a ditadura, construir o socialismo - só poderiam ser feitos através da luta armada. Isso aí eu não tenho dúvida nenhuma. Eu era totalmente fechado, eu não tinha nenhum tipo de dúvida a respeito" (COSTA, 2009, p. 10).

Se a constituição da personagem Leonardo aponta para um problema ético de primeira ordem no bojo dos acordos de compromisso moral com a luta, não menos problemático nesse mesmo prisma é o processo de humanização do militar em plena caçada aos guerrilheiros. Em uma das passagens do diário, em que Leonardo conta a respeito de seu contato com uma família de agricultores cujo alimento havia sido levado por militares, temos a narração de um breve contato entre um soldado e umas crianças: "contudo, um soldado tinha mostrado às crianças as fotos de seus filhos e contou-Ihes, com lágrimas nos olhos, que, quando deixou sua casa, não sabia que estava indo para uma guerrilha de verdade. Tinha medo de nunca mais ver sua família de novo" 
(GRAMMONT, 2015, p. 36). Aqui o leitor é convocado a fazer um balanço do que sejam as dificuldades enfrentadas por um soldado militar, fortemente armado e sempre amparado por outros de seu grupamento, e as enfrentadas por um guerrilheiro exausto, faminto e isolado de seu grupo. Tal como o guerrilheiro, a proposta parece ser a de fazer com que o leitor compreenda que o militar também é vítima e sofre como todo ser humano.

Duas passagens do romance carregam o peso da inverossimilhança e traduzem de forma bastante acentuada um certo descuido, ou poderíamos chamar de um certo desleixo narrativo. Ao ser capturado pelos militares, Leonardo conta que pediu um lápis e continuou a escrever no diário que carregava consigo. Trata-se de uma situação muito duvidosa de ocorrer nesse contexto de prisão. Experiências diversas vividas por personagens de outros romances, bem como por ex-militantes, mostram que as prisões se fazem notar pelo excessivo uso da força, principalmente longe dos olhos da população, como no caso da Guerrilha do Araguaia.

No romance Em câmara lenta, já referido aqui, a circunstância inicial da prisão que culmina com a tortura e morte da personagem central é narrada de maneira que à vítima não se concede tempo para elaborar qualquer forma de explicação ou algum pedido de clemência. A ação violenta é iniciada com a vítima detida, mesmo que não esboce reação alguma.

Ela correu por entre os carros e quase todos os policiais foram atrás dela, atirando sempre [...]. Os policiais pararam de atirar e um deles conseguiu alcançá-la, segurando-a por um braço. Ela se voltou e bateu com a coronha do revólver na cabeça do policial. Este lançou-se sobre ela e ambos rolaram pelo barranco [...]. Ele agarrou sua perna e, enquanto ela procurava não perder o equilíbrio, outros policiais chegaram. Cercaram-na e caíram sobre ela acertando socos em seu rosto, pontapés em suas costas, tentando segurá-la [...]. Puxaram-na pelas algemas: ela caiu ao chão e foi arrastada, rasgando a roupa e a pele macia de encontro às pedras do terreno (TAPAJÓS, 1979, pp. 87-89).

Nessas circunstâncias, a permissão para que o prisioneiro permaneça com seu diário e continue escrevendo sugere uma estranha benevolência dos militares para com um sujeito considerado inimigo da lei. 
Bem alinhado a esse caráter inverossímil é o episódio em que Sofia vai até a casa do coronel aposentado e consegue com extrema facilidade não apenas ter acesso e contato direto com o idoso, mas também recebe de sua filha, Laura, anotações de trabalho da época em que seu pai era coronel. A experiência recente de comissões de investigação tem mostrado o quanto é difícil ter acesso a depoimentos de militares aposentados acusados de práticas de tortura durante a ditadura. Mesmo quando isso acontece, pouca informação é revelada.

No âmbito da ficção, essa dificuldade de ouvir um militar pode ser minimizada, pois o escritor tem inúmeros recursos narrativos para dar voz a ele. Curiosamente, no romance de Grammont, que de maneira declarada procura apresentar as duas visões a respeito da Guerrilha do Araguaia (a dos militares e a dos guerrilheiros), a voz mais representativa da perspectiva militar é silenciada. O coronel é um senhor muito doente, que não enxerga e não fala, em razão de um derrame sofrido. É certo que essa estratégia contribui para a consecução da história, mas, do ponto de vista ético, produz um problema sério para o que a obra intenta representar.

O romance ainda possui três vozes responsáveis diretamente pela guinada revisionista. Taco é uma personagem que havia sido guerrilheiro junto com Leonardo. Pelo menos duas vezes Sofia mantém contato com ele em busca de informações sobre o irmão. No segundo contato, ao ser interrogado a respeito de suas lembranças, o antigo guerrilheiro responde: "Era outro tempo, nós éramos jovens, muita adrenalina correndo nas veias, nos achávamos os donos da verdade... Hoje, quando penso no que vivemos..." (GRAMMONT, 2015, p. 80). Mais adiante, em conversa com Sofia a respeito de Leonardo, seu amigo Marcos Ihe diz: "Essa guerrilha foi uma mancha na história do Brasil, Sofia, mas sobretudo pela estupidez, pela inutilidade de tudo. Um punhado de jovens que se enfiam no campo, num país desse tamanho, sonhando em mudar o mundo..."; "tudo não passou de um grande delírio, isso sim. Dos dois lados". Por fim, em Cuba, em conversa com outro antigo guerrilheiro, Sofia ouve o seguinte conselho: 
Olvida el passado. Tu hermano está vivo. Está aqui - apontou um lugar no peito dela, sem tocá-la. - Está em tu corazón. No te dejará nunca, hasta que te mueras. Todos vamos a murir y no llevamos nada. Nada de todo esto por lo que luchamos en la vida. Lo único que tenemos son nuestros recuerdos, nuestros sentimientos. Esto es lo que podemos dejarles a nuestros hijos... (GRAMMONT, 2015, p. 153) ${ }^{2}$

Aqui, a expectativa de reconciliação com o passado se faz por meio da necessidade de esquecimento, o que pode contribuir para o apaziguamento com o presente da personagem Sofia. A narrativa sugere, então, um aprendizado, o de que para viver bem, é necessário esquecer o passado doloroso, ainda que os perpetradores dessa dor extrema não sejam punidos. Esse processo é marcado de maneira emblemática pela revelação de que o coronel Monteiro envia à Luísa o diário de Leonardo e Mariana e adota a filha do casal para, por meio dessa atitude simbólica essencialmente humana e humanizadora, pedir perdão. O tom conciliatório do romance é celebrado nesse episódio com efeito catártico, perseguido por Sofia ao longo de toda a narrativa: "Está certo o que você está fazendo, Sofia, buscando compreender o que houve, para fazer a catarse do acontecido" (GRAMMONT, 2015, p. 174).

Em estudo sobre a obra de Jorge Semprun, Susan Rubin Suleiman (2006) aponta como marca singularizadora das narrativas testemunhais do escritor espanhol, o processo de revisão. Segundo Suleiman, esse processo se repete especificamente nos livros Um belo domingo (1980), A escrita ou a vida (1994), e O morto certo (2001). No contexto dessas histórias, um episódio é comum: a chegada de Semprun ao campo de Buchenwald. Mas a repetição desse evento não é estática, em que o "eu" narrador não é capaz de negociar (rever) o vivido, a partir de uma memória traumatizada e fixada na repetição inalterada. Ao contrário, cada vez que retorna, na sequência das obras, ao momento do acidente traumático (FREUD, 2010), Semprun estaria renegociando a memória, numa perspectiva de reinterpretação do passado. $A$ compreensão de que todo fazer narrativo é constituído pelo que Suleiman chama "ciladas da memória" (SULEIMAN, 2006, p. 135) (pitfalls of memory), ou

\footnotetext{
2 "Esqueça o passado. Teu irmão está vivo. Está aqui [...]. Está em teu coração. Não te deixará nunca, até que você morra. Todos vamos morrer e não levamos nada. Nada de tudo o que lutamos em vida. A única coisa que temos são nossas recordações, nossos sentimentos. Isso é o que podemos deixar para nossos filhos".
} 
seja, os erros e imprecisões essencialmente humanos, estaria diretamente ligada a esse processo de constante revisão do passado.

O ponto crucial dessa formulação de Suleiman para os propósitos de nosso estudo reside no significado desse processo de revisão. Rever 0 passado não é o mesmo que negá-lo. A insistência de Semprun nessa revisitação aponta para uma incessante tentativa de correção da memória, abalada que foi por toda a experiência traumática vivida pelo próprio escritor na condição de prisioneiro. Sua postura ética em torno da representação do terror não visa relativizá-lo ou negá-lo, mas recompor a memória a seu respeito e mantê-la em constante processo de reinterpretação.

$\mathrm{O}$ que, em linhas gerais, no romance de Grammont parece ser mais incisivo é a necessidade de redistribuir em grau de igualdade a responsabilidade pelo terror. Militares e militantes estariam em um mesmo patamar no que diz respeito ao uso da violência. Esse aspecto atribui a Palavras cruzadas um caráter negacionista. O elemento fulcral do romance não é a representação da violência entre militares e militantes (comum à maior parte da produção literária a respeito do assunto), mas a violência produzida dentro da própria organização de esquerda a qual pertence Leonardo, o que estimula a construção de imagem negativa de quem se opõe ao regime militar.

\section{Considerações finais}

As questões levantadas pelo livro de Grammont são de extrema importância e merecem concentrada atenção. Entretanto, no contexto da narrativa, parece haver um esvaziamento do espaço do debate crítico, talvez pela frágil perspectiva crítica da protagonista. É fácil perceber que não há confrontação de ideias de maneira satisfatória. Os poucos questionamentos que Sofia faz são rapidamente respondidos de maneira a the convencer da inutilidade da luta travada por seu irmão.

Assim, longe de tentar construir um esquema maniqueísta de interpretação, pensamos que um aspecto importante do ponto de vista ético que poderia ter tido um tratamento mais amplo no cerne da narrativa, é o debate em torno da violência do opressor e da violência do oprimido. 
Conforme Jacob Gorender (1990), a violência é um elemento constitutivo do nosso cotidiano. É por meio de sua expressão coerciva e normalmente velada que a sociedade burguesa é organizada. No contexto da ditadura militar no Brasil, essa violência teria transcendido os "véus" que a camuflavam e se tornado institucionalizada: "o poder militar fez questão de torná-la demonstrada" (GORENDER, 1990, p. 226). Da censura, passando pelas práticas de tortura e eliminação física de opositores ao regime, a ditadura fez do uso abusivo e desumanizante da violência sua principal estratégia para manutenção do poder.

Do lado de quem sofreu diretamente com essa violência, não houve passividade. A resistência à ditadura também fez uso da violência, entretanto, como afirma Gorender, "nenhum dos lados julga pelo mesmo critério as duas violências" (1990, p. 235). Há a violência do opressor e a violência do oprimido. $A$ deste, praticada em reação à daquele. $A$ violência do opressor obedece a uma sistematização, a uma racionalização dessas práticas, normalmente fundadas num total desrespeito ao que prevê a Declaração Universal dos Direitos Humanos e os demais documentos que regulamentam a ação militar em conflitos armados.

Olhando por esse ângulo, somos tencionados novamente a pensar que a busca de Sofia pela verdade a respeito do desaparecimento de seu irmão corresponde, no plano da ficção, a uma busca pela reconciliação com o passado que traumatizou sua mãe, seu pai e a ela mesma (trauma herdado), e com os próprios responsáveis pelo desaparecimento de Leonardo, sem exigência de reparação.

Paul Ricœur, no capítulo final de seu longo estudo sobre $A$ memória, a história, o esquecimento, afirma que todo ato injustificável é constituído por um excesso de algo que está além da possibilidade do perdão, a não ser que, diante dessa possibilidade, o culpado seja punido: "nessa dimensão social, só se pode perdoar quando se pode punir" (RICCEUR, 2007, p. 476). Mais adiante, o autor acrescenta que:

Onde há regra social, há possibilidade de infração; onde há infração há o punível, a punição visando a restaurar a lei ao negar simbólica e efetivamente o dano cometido à custa de outrem, a vítima. Se o perdão fosse possível nesse nível, ele 
consistiria em tirar a sansão punitiva em não punir quando se pode e se deve punir. Isso é impossível diretamente, pois o perdão cria impunidade, que é uma grande injustiça (RICOEUR, 2007, p. 476).

$\mathrm{Na}$ esteira desse pensamento, podemos dizer que dentro do atual debate que se estabelece entre políticas de memória e políticas de esquecimento, especialmente no contexto das ditaduras latino-americanas, o romance de Grammont parece possuir sérias ligações com essa segunda perspectiva. Isso se torna, como já dissemos anteriormente, um desafio para a crítica literária atual, pois o surgimento do romance coincide com um quadro de debates bastante controverso a respeito da memória da ditadura militar brasileira. Num momento em que o país tenta, ainda que de maneira insatisfatória, recuperar a memória da ditadura por meio de ações empreendidas pela Comissão da Verdade, e em que nenhuma ação mais efetiva no plano da justiça se faz a fim de punir os responsáveis pela violação de direitos humanos no período ditatorial, propor o apaziguamento entre 0 opressor e a família de quem foi oprimido, de quem não se pôde enterrar o corpo e, assim, recompor a vida, pode corresponder, no campo interpretativo, a uma desconfortante atitude que tende a negociar o esquecimento, estimular a impunidade, legitimar a continuidade de práticas autoritárias e contribuir com a repetição do terror. 


\section{REFERÊNCIAS}

BENJAMIN, Walter. Origem do drama barroco alemão. São Paulo: Brasiliense, 1984.

. "O narrador: considerações sobre a obra de Nikolai Leskov". In: Magia e técnica, arte e política: ensaios sobre literatura e história da cultura. São Paulo: Brasiliense, 1994, pp. 197-221.

COSTA, Carlos Augusto Carneiro. Militância política, pensamento e literatura: Renato Tapajós e o regime militar no Brasil. Literatura e Autoritarismo. Dossiê "Cultura Brasileira Moderna e Contemporânea". pp. 129-146, dez. 2009. Disponível em: <http://coralx.ufsm.br/grpesqla/revista/dossie02/RevLitAut_art12.pdf>. Acesso em: 10 jan. 2010.

CHKLOVSKI, Victor. A arte como procedimento. In: TOLEDO, Dionísio de Oliveira (org.). Teoria da Literatura - formalistas russos. 2. ed., Porto Alegre: Globo, 1978, pp. 39-56.

FREUD, Sigmund. Além do princípio do prazer (1920). In: História de uma neurose infantil: ("O homem dos lobos"); Além do princípio do prazer e outros textos (1917-1920). São Paulo: Companhia das Letras, 2010, pp. 161-239. (Obras completas, volume 14)

GORENDER, Jacob. Combate nas trevas. São Paulo: Ática, 1990.

GRAMMONT, Guiomar de. Palavras cruzadas. Rio de Janeiro: Rocco, 2015.

HARTMAN, Geoffrey H. Holocausto, testemunho, arte e trauma. In: NESTROVSKI, Arthur; SELIGMANN-SILVA, Márcio (org.). Catástrofe e representação: ensaios. São Paulo: Escuta, 2000, pp. 207-235.

RICCEUR, Paul. O perdão difícil. In: A história, a memória, o esquecimento. Campinas, SP: Editora da UNICAMP, 2007, pp. 465-512.

SULEIMAN, Susan Rubin. Revision: Historical Trauma and Literary Testimony. In: Crises of Memory and the Second World War. Cambridge, London: Harvard University Press, 2006, pp. 132-158.

TAPAJÓS, Renato. Em câmara lenta. São Paulo: Alfa-Ômega, 1979. 